\title{
DEVELOPMENT OF CRYPTO COINS AND THEIR PLACE IN THE ECONOMY
}

\author{
DOI: 10.17261/Pressacademia.2021.1491 \\ PAP- V.14-2021(17)-p.80-83
}

Erdal Arslan' ${ }^{1}$, Gullu Guzel $^{2}$

${ }^{1}$ Selcuk University, Department of Economics, Konya, Turkey. erdalarslan@selcuk.edu.tr, ORCID: 0000-0003-4892-2963

${ }^{2}$ Selcuk University, Department of Economics, Konya, Turkey. gullu.guzel58@gmail.com, ORCID: 0000-0002-0874-3760

\section{To cite this document}

Arslan, E., Güzel, G.,, (2021). Development of crypto coins and their place in the economy. PressAcademia Procedia (PAP), 14, 80-83.

Permanent link to this document: http://doi.org/10.17261/Pressacademia.2021.1491

Copyright: Published by PressAcademia and limited licensed re-use rights only.

\begin{abstract}
Purpose- The first cryptocurrency, Bitcoin, was launched on January 3, 2009 and has allowed the creation of many crypto assets until today. Bitcoin, which is considered the father of cryptocurrencies, is limited to 21 million by specifying the maximum number that can be produced in the genesis block. Bitcoin, which has a more stable market value thanks to the large market and transaction volume it has acquired today, has turned into a virtual currency used by much more people than in the past. This study aims to provide information about the large financial system created by bitcoin and other cryptocurrencies, as well as to develop new perspectives on how this new financial system can follow in the future. In addition, it is a preliminary study that can be used as a resource in the future on this field.

Methodology- In this study, crypto assets, bitcoin and altcoins, which have been used for many years, are examined within the titles and their definitions, features and usage areas are mentioned. Afterwards, the advantages and risks of blockchain technology are discussed in terms of countries, and the approaches of countries towards cryptocurrencies are examined. Finally, the legal regulations that are expected to be taken in this area are given.

Findings- Crypto assets are becoming virtual assets that can take over the exchange activity, replacing classical money over time. The listed companies in the markets where these assets are traded charge a very low commission amount in return for the exchange transaction. As a result of this advantage, crypto money holders can keep the chance to trade the assets they have in their wallets at any time. Although its legal basis has not yet been established, crypto assets are increasing in demand due to their positive aspects such as low transaction costs, easy transfer and high earnings rates.

Conclusion- As a result, cryptocurrencies have turned into virtual assets that are heavily traded for investment purposes today. Although it has many positive aspects, the fact that its legal foundations have not been laid negatively affects the trust in these assets. These assets, whose current market value has reached 1.7 trillion dollars, have been accepted in international markets and have started to attract attention especially in their states. For this reason, while many states around the world have accelerated the infrastructure work for cryptocurrencies, El Salvador has broken new ground and declared Bitcoin the official currency with the bill passed by the Senate on June 6, 2021.
\end{abstract}

Keywords: Cryptocurrency, financial markets, bitcoin, blockchain, stock market

JEL Codes: G10, G15, C01,

\section{KRIPTO PARALARIN GELIŞiMi VE EKONOMIDEKI YERI}

\section{ÖZET}

Amaç- Illk kripto para birimi olan Bitcoin 3 Ocak 2009`da hayata geçmiş ve günümüze kadar birçok kripto varlığın oluşmasına olanak sağlamıştır. Kripto paraların babası sayılan Bitcoin en fazla üretilebilecek sayı olarakta genesis blokta belirtilerek 21 milyonla sınırlandırılmıştır. Günümüzde edindiği büyük market ve işlem hacmi sayesinde daha stabil bir piyasa değerine kavuşan Bitkoin eskiye nazaran çok daha fazla insanın kullandığı bir sanal para haline dönüşmüştür. Bu çalışma, bitcoin ve diğer kripto paraların oluşturduğu büyük finansal sistem ile ilgili bilgi verebilmeyi aynı zamanda oluşan bu yeni finansal sistemin gelecekte nasıl bir yön izleyebileceği hakkında yeni bakış açıları geliştirmeyi amaçlamaktadır. Ek olarak ise, bu alan ile ilgili gelecek zamanlarda kaynak olarak kullanılabilecek öncül bir çalışma niteliği taşımaktadır. Yöntem- Bu çalışmada uzun yıllardır kullanılan kripto varlıklar, bitcoin ve altcoinler başlıklar dahilinde incelenerek tanımlarına, özelliklerine ve kullanım alanlarına değinilmektedir. Devamında ülkeler açısından blockchain teknolojiisinin avantajları ve riskleri ele alınarak, ülkelerin kripto paralara karşı yaklaşımları incelenmektedir. Son olarak ise bu alanda atılması beklenen yasal düzenlemelere yer verilmektedir.

Bulgular- Kripto varlıklar zamanla klasik paranın yerini alarak takas faaliyetini üstlenebilecek sanal varlıklar haline gelmektedir. Bu varlıkların işlem gördüğü piyasalardaki borsa şirketleri, yapılan takas işlemi karşılığında oldukça düşük bir komisyon miktarı talep ederler. Bu avantaj 
neticesinde kripto para sahipleri istedikleri herhangi bir zamanda cüzdanlarında bulundurdukları varlıkları değiş-tokuş (trade) yapma şansını ellerinde tutabilmektedirler. Henüz yasal zemininin oluşmamasına rağmen düşük işlem maliyetleri, kolay transferi ve yüksek kazanç oranları gibi olumlu yönleri nedeniyle kripto varlıklar, giderek talebini arttırmaktadır.

Sonuç- Sonuç olarak, kripto paralar günümüzde yoğun olarak yatırım amacı ile alım ve satımı yapılan sanal varlıklar haline dönüşmüştür. Her ne kadar olumlu yönleri fazla olsa da yasal temellerinin atılmamış olması bu varlıklara duyulan güveni olumsuz şekilde etkilemektedir. Şuan ki piyasa değeri 1.7 trilyon dolara ulaşan bu varlıklar uluslarası piyasalarda kabul görerek özellikle devletlerinde ilgisini çekmeye başlamıştır. Bu nedenle dünya üzerindeki birçok devlet kripto paralar için alt yapı çalışmalarına hız kazandırken El Salvador ise bir ilki gerçekleştirerek 6 Haziran 2021 tarihinde senatodan geçen tasarı ile birlikte Bitcoin'i resmi para birimi ilan etmiştir.

Anahtar Kelimeler: Kripto para, finansal piyasalar, bitcoin, blok zincir, borsa

JEL Kodları: G10, G15, C01

\section{GiRiş}

İnsanlık tarihi boyunca mal ve hizmet alabilmek amacıyla çeşitli ödeme yöntemleri uygulanmıştır. Sosyal yapının evrilmesiyle eş zamanlı olarak ödeme yöntemlerindede çeşitlenme olmaktadır. Görevini yerine getirmekte zorlanan ödeme enstrümanları zamanla yerini daha etkin ödeme yöntemlerine bırakmaktadır. Gelişen her yöntemdeki ortak yön kullanıcısının işini bir önceki yönteme oranla dahada kolaylaştırmasıdır. Bu çerçevede faydalanılan yöntemlerin sayısı zamanla artış göstermiş olsa da takas haricindeki araçların tamamı resmi bir merkezce çıkarılmış paralardan faydalanılarak yapılmaktadır.

Ancak son zamanlarda oldukça ciddi kullanım oranlarına sahip olan merkezi bir otoriteye sahip olmayan, kullanımı diğer ödeme yöntemlerine göre daha hızlı ve daha düşük maliyetli olan kripto varlıklar hayatımıza giriş yapmıştır. Kripto paralar, güvenliğini blok zincire ve arkasındaki algoritmaya dayandıran, kişilerin talepleri doğrultusunda para yerine kullanılabilen ödeme ve para birimi şeklinde açıklanmaktadır. Elbette herhangi bir otoriteden bağımsız olması nedeniyle hem olumsuz hem de olumlu yönlerini bünyesinde bulundurmaktadır. Bu çalışma ile bahsi geçen sanal varlıkların mevcut iktisadi sisteme nasıl entegre olduğu ve bu sistemi ne oranda etkileyebileceği hem avantaj hem de dezevantajlarına bakarak incelenecektir. Son olarak ise bağımsız bir varlık modeli olan kripto paraların sürdürülebilirliği hakkında bilgilere ulaşmak amaçlanmakatadır.

\section{LITERATÜR}

Carpenter (2016), Ocak 2012 ve Mayıs 2016 dönemi arasındaki verilerden faydalanarak oluşturduğu çalışmasının neticesinde, Bitcoin değerinin oynak bir seyir izlemesine rağmen oldukça yüksek bir getiri oranına sahip olduğu ve geri kalan finansal varlıklarla düşük korelasyon ilişkisi içermesi nedeniyle oldukça önemli bir portföy çeşitlendirme enstrümanı olduğunu belirtmiştir.

Moore ve Stephen (2016), çalışmalarında gelecek dönemlerde ülkelerin merkez bankalarının uluslarası rezerv miktarlarının bir kısmını kripto varlıklara ayırmasının olası avantaj ve dezevantajlarına yer vermektedirler. Çalışmanın neticesinde, bu varlıkların gerçekleştirilen birçok işlemi kolaylaştırabileceğini ancak rezerv içindeki oranının aşırı dalgalı olmasından dolayı sınırlı tutulması gerektiğini öne sürmüşlerdir.

Corbet vd. (2018), üç ana kripto varlığı seçerek diğer iktisadi varlıklarla arasındaki oynaklık ve getiri oranlarını incelemişlerdir. Çalışmanın neticesinde kripto varlıkların kısa dönemli olarak yatırımcılarına avantaj getirebileceğine ve ekonomide meydana gelen ani şoklardan en minimum seviyede etkilendiklerini ortaya çıkarmışlardır.

Karaağaç ve Altınırmak (2018), belirlenmiş on kripto varlığın kendi aralarında olan etkileşimleri üzerinde durmuşlardır. Johansen Eşbütünleşme Analizi ile Granger Nedensellik Testinden faydalanarak, Bitcoin'in, Litecoin'in ve NEM'in Bitcoin Cash'in Granger nedeni olduğu ortaya çıkarılmıştır.

Kostakis ve Giotitsas (2014), Bitcoin gibi sanal varlıkların politika üzerindeki etkisini, dijital para biriminin yükselişi, fayda ve zararlarını araştırmaktadırlar. Farklı bir zemine sahip olan sanal paraların "dağınık kapitalizmi” in bir örneği olduğunu ve üstün bir teknolojik gelişme olduğu fikrini öne sürmüşlerdir.

\section{VERI VE YÖNTEM}

Bu çalışmada en yüksek piyasa değerine sahip olan ilk 10 kripto varlığın 2021 yılı içi ABD doları üzerinden değerleri incelenmiştir. Bu Kripto varlıklar ise Bitcoin, Ethereum, Binance Coin, Cardano, Tether, XRP, Solana, Polkadot, USD Coin, Dogecoin'dir. https://coinmarketcap.com/ (13.10.2021)

Tablo 1: Kripto Para Birimlerinin Piyasa Değeri (2021)

\begin{tabular}{l|l|l|}
\hline \multicolumn{1}{l}{ İsim } & \multicolumn{1}{l}{ Fiyat } & \multicolumn{2}{c}{ Market Hacmi } \\
\hline Bitcoin (BTC) & $55.100 \$$ & $1.04 \mathrm{~T} \$$ \\
\hline Ethereum (ETH) & $3.457 \$$ & $408.41 \mathrm{~B} \$$ \\
\hline Binance Coin (BNB) & $458 \$$ & $77.15 \mathrm{~B} \$$ \\
\hline Cardano (ADA) & $2.12 \$$ & $69.79 \mathrm{~B} \$$ \\
\hline Tether (USDT) & $0.99 \$$ & $68.76 \mathrm{~B} \$$ \\
\hline
\end{tabular}




\begin{tabular}{|l|l|l|}
\hline XRP (RIPPLE) & $1.09 \$$ & $51.08 \mathrm{~B} \$$ \\
\hline Solana (SOL) & $145 \$$ & $43.92 \mathrm{~B} \$$ \\
\hline Polkadot (DOT) & $35 \$$ & $34.82 \mathrm{~B} \$$ \\
\hline USD Coin (USDC) & $1 \$$ & $32.82 \mathrm{~B} \$$ \\
\hline Dogecoin (DOGE) & $0.2238 \$$ & $29.53 \mathrm{~B} \$$ \\
\hline
\end{tabular}

Tablo 1' de piyasada en yüksek değere sahip ilk 10 kripto paranın fiyat ve market hacmi bulunmaktadır. Bu tabloya göre ilk sırada 1.04 Trilyon \$'Iık market hacmi ile Bitcoin bulunmaktadır. 13 Ekim itibariyle büyük bir düşüş sonrası fiyatı tekrardan 55.100 \$ seviyelerine kadar yükseliş gösermiştir. Tarihteki en yüksek market hacmi nedeniyle ülkelerin dikkatini çekerek ilk kez El Salvador tarafından resmi para birimi olarak kabul edilmiştir. Firmalar ise enflasyondan kaçınabilmek amacıyla faaliyerlerini Bitcoin üzerinden yapmaya başlayarak piyasa hacminin artmasına katkıda bulunmaktadırlar.

Bitcoini 2. sıra ile takip eden Ethereum ise kullanıcılarına bağlı olduğu blockchain sistemi üzerinden yeni yazılımlar üretebilme olanağı sağlamaktadır. Bu coin ile amaçlanan, kişisel veriler gibi bilgilerin başka şahışlarca depolanmasını ve kullanılmasını önlemektir. Bugün toplumların internet üzerinden yaptığı bütün işlemler; alışveriş, banka işlemleri, sosyal medya gibi verilerimiz özel data banklarda saklanmasına ragmen bu verilerin nasıl amaçlar için kullanıldığı ise tamamen belirsizlik içindedir. Bu bağlamda ise Ethereum sistemi elde edilen verileri bütünüyle dağınık ve anonim bir şekilde binlerce cihaz üzerinden korumaktadır. Bu verilerin güvenliğini sağlayarak internetin merkezsiz bir platforma evrilmesine olanak sağlamaktadır. Ek olarak ise, Bitcoine nazaran daha stabil bir fiyat seviyesine sahip olmasından dolayı en güvenilir kripto paralar arasına girerek yatırımcılar için oldukça cazip bir coin haline gelmiştir. Şuan ki değeri 3.457 olan Ethereum'un market hacmi ise, 408 Milyar \$'dır.

3. sırada ise Binance kripto para değişim borsasının oluşturduğu Binance Coin (BNB) yer almaktadır. Kullanıcısının sayısına göre dünyanın en büyük borsalarının başında gelen Binance, borsa hacmi ile orantılı olarak BNB'nin hacmi ve değerinde de kayde değer bir yükseliş yakalamıştır. BNB'nin güncel değeri 458 \$iken market hacmi ise 77 milyar \$ seviyelerindedir.

4. sırada ise fiyatı 2.12 \$ seviyelerinde seyreden Cardano (ADA) yer almaktadır. Bu coin'in temel hedefi ise kripto para göndermek ve almak amacıyla hareket eden bir sistem oluşturabilmektir. Bu kripto varlık, paranın gelecek versiyonunu yansıtmanın yanında kriptografi ile güvenli bir şekilde doğrudan transferleri mümkün kılmaktır. Cardano'nun güncel market hacmi ise 69.79 Milyar \$ seviyelerine ulaşmıştır.

Tether ise kripto para dünyasında, ABD dolarının sanal versiyonu olarak işlem gören stabil bir coinidir. Değeri her zaman 10 USDT (Tether) = 10 \$ şeklinde işlem görmektedir. Bu coini 2015 yılında piyasaya süren Tether Limited Şirketinin beyanına göre piyasada olan her bir Tether (USDT) karşılığında kasasında'da 1 \$ bulunmaktadır. Ortaya çıkış amacı ise kripto para borsalarında reel para biriminin oldukça düşük komisyonlarla transferini yani dolar cinsinden işlem yapabilme avantajını sağlamaktır. Güncel fiyatı 0.99 olan Tether'in market hacmi ise, 68 Milyar \$ seviyelerinde seyretmektedir.

6. sırada yer alan XRP (Ripple) 2012 yılında bir ödeme ağı sistemi yaratabilmek amacıyla ortaya çıkarılmışır. XRP'yi diğer coinlerden ayıran en önemli özelliği ise altyapısının merkezi bir sisteme dayandırılmasıdır. Blockchain sisteminde yer almasına ragmen işlemi görülen bütün defterler şirketçe yönetilmektedir. Bu sanal para biriminin hedefi, yüksek miktarlardaki parasal değerlerin hızlı ve ucuz bir şekilde, blockchain teknolojisi üzerinden transferinin sağlanmasıdır. Piyasa değerinin en yüksek altıncı kripto para olması ve yüksek işlem hacimleri sayesinde birçok kripto para borsasında işlem görmektedir. Bu durum ise hem tanınırlığını hem de erişilebilirliğini artırmaktadır. Güncel değeri $1.09 \$$ olan XRP'nin market hacmi ise 51 Milyar \$ seviyelerinde dalgalanmaktadır.

XRP'yi 7. sıra ile takip eden Solana, yüksek performans seviyesine sahip olan aynı zamanda izne gereksinim duymayan açık kaynakıı bir sanal para çalışmasıdır. Solana'nın temel hedefi, blockchain dünyasının en büyük problemi olan ölçülebilirlik sorununu optimize şekilde çözmeye çalışmaktır. Saniyede 50.000 'den daha fazla işlemi yerine getirebilen Solana, FTX borsası, Sam Bankman Fried gibi birçok kripto para taraftarının ilgisini çekerek zamanla market hacmini 43 Milyar \$ seviyelerine çıkarmıştı. Bir Solana'nın güncel değeri ise şuan $145 \$$ seviyelerinde seyretmektedir.

34 Milyar \$'lık market hacmi ile Solana'nın hemen gerisinden gelen Polkadot (DOT), merkeziyetsiz internet sitelerini ve herhangi bir izne tabi olmayan topluma açık ağları blockchain teknolojisi ile birbirine bağlayan ve güvenli bir şekilde merkeziyetsiz bilgi alışverişini sağlamayı hedefleyen bir kripto para çalışmasıdır. Polkadot'un en büyük avantajı ise parçalanmış birçok ağ temeliyle, gerçekleştirilen işlemlerin hızının azalmasının önüne geçmesidir.

USD Coin (USDC) ise, Tether'in çalışma prensibine benzer olarak 1 USDC= 1 \$ şeklinde sabitlenmesi hedeflenmiştir. Piyasaya sürülen her bir USDC karşılı̆ıında 1 ABD \$’ı da belirli özel bankaların hesabında tutulmaktadır. Bu coin'in ortaya çıkmasının amacı, şeffaf bir zeminde itibari paranın akıllı kontratlar ile etkileşimini sağlayarak, bu paraların blokzincir üzerinde kullanılmasını kolaylaştırmaktır.

Son olarak ise , blockchain teknolojisinde herhangi bir inovasyon geliştirme amacı gütmeyen sadece eglenceli bir ödeme sistemi oluşturmak amacıyla geliştirilen Dogecoin(DOGE), ulaştığı büyük işlem hacmi sayesinde birçok kripto varlığı geride bırakarak onuncu en yüksek işlem hacmine sahip olan sanal para birimi olmuştur. Güncel değeri 0.22 olan Dogecoin'in market hacmi ise 29 Milyar \$ seviyelerine ulaşmıştır

\section{BULGULAR}

Aşağıda tablo 2'de 2021 yılı için dünya genelinde en yüksek değere sahip ilk 8 varlık bulunmaktadır. 
Tablo 2: Piyasa Değerine Göre En İyi Varlıklar (2021)

\begin{tabular}{|l|l|l|l|l|l|l|l|l|}
\hline İsim & Altın & Apple & Microsoft & Saudi Aramco & Google & Amazon & Gümüş & Bitcoin \\
\hline Fiyat & $1.769 \$$ & $139.62 \$$ & $295.20 \$$ & $9.86 \$$ & $2.744 \$$ & $3.268 \$$ & $22.81 \$$ & $55.100 \$$ \\
\hline Market Hacmi & $11.234 \mathrm{~T} \$$ & $2.307 \mathrm{~T} \$$ & $2.218 \mathrm{~T} \$$ & $1.971 \mathrm{~T} \$$ & $1.830 \mathrm{~T} \$$ & $1.655 \mathrm{~T} \$$ & $1.284 \mathrm{~T} \$$ & $1.042 \mathrm{~T} \$$ \\
\hline
\end{tabular}

Gittikçe artan market hacmi ile birlikte kripto varlıklar Dünya genelinde en yüksek değere sahip varlıklar arasında Bitcoin 8. sırada Ethereum ise 19 sırada yerini almaktadır. Alibaba, JPMorgan Chase ve Tesla'nın değerini geride bırakan bitcoin'in şuan önündeki ilk rakibi ise 7. Sırada bulunan 1.284 Trilyon \$’lık değeri ile gümüş olacaktır. Değerindeki bu hızlı yükseliş sayesinde insanlar tarafından da en çok tercih edilen yatırım varlıklarından biri olmaktadır. Fiyat ve hacimdeki hızlı artışlar nedeniyle yatırımcılar tarafından güven kazanan bu coinler giderek ekonomik sisteme kendini entegre etmeyi başardığı gözlemlenmekte ve gelecekte bu sistemin daha da yaygınlaşacağı öngörülmektedir.

\section{SONUÇ}

2009 yılında Bitcoin'in borsalarda işlem görmesinden hemen sonra, çeşitli kripto varlıklarda bu borsalarda yerini almaya başlamıştır. Portföylerini çeşitlendirmek isteyen yatırımcıların dikkatini çekmeye başlaması ile paralel olarak kripto varlık projelerinde de bir çeşitlendirme yaşanmaktadır. Bunlara ek olarak bu varlıkların fiyatları ve market hacimlerinde de hızlı bir yükseliş yaşanmaktadır.

Bu çalışmada öncelikle piyasada en çok hacime sahip olan ilk 10 koinin ortaya çıkış amaçları ve özellikleri üzerinde durularak 13 Ekim 2021 yılı itibariylede bulunduğu değerleri ve kripto piyasası içindeki hacimlerine dikkat çekilmeye çalışılmıştır. Daha sonra ise, kripto paraların toplam piyasa hacminin Dünya genelinde en değerli varlıklar arasındaki sırası incelenerek yeni tekno-ekonomik sisteme nasıl hızlı entegre olduğu gözlemlenmektedir.

Kripto paraların giderek yaygınlaşması ile birlikte ülkelerin oldukça dikkatini çekerek, bu alanda altyapı çalışmalarına ve yasal zemin oluşturmak hakkında araştırmalara başlanmıştır. Ancak hızlı bir gelişme yakalamış olsa dahi birçok ülkenin yasal kısıtlamaları nedeniyle önümüzdeki dönemlerde bu varlıkların geleneksel paranın yerini alması zor görünmektedir. Fakat yatırımcısını giderek arttırmaya devam edeceğide kaçınılmaz bir gerçektir.

\section{KAYNAKÇA}

Betül, Ü. Z. E. R., \& Müdürlüğü, Ö. S. G. Sanal Para Birimleri.

Bitlo, [Çevrimiçi Kaynak]. Https://Www.Bitlo.Com/ [Erişim Tarihi: 13 Ekim 2021].

Carpenter, A. (2016). Portfolio Diversification With Bitcoin. Journal Of Undergraduate Research In Finance, 6(1), 1-27.

Corbet, S., Lucey, B., \& Yarovaya, L. (2018). Datestamping the Bitcoin and Ethereum bubbles. Finance Research Letters, $26,81-88$.

Companiesmarketcap, [Çevrimiçi Kaynak]. Https://Companiesmarketcap.Com/Assets-By-Market-Cap/ [Erişim Tarihi: 13 Ekim 2021].

Coinmarketcap, [Çevrimiçi Kaynak]. Https://Coinmarketcap.Com/ [Erişim Tarihi: 13 Ekim 2021].

Çetinkaya, Ş. (2018). Kripto paraların gelişimi ve para piyasalarındaki yerinin Swot analizi ile incelenmesi. Uluslararası Ekonomi ve Siyaset Bilimleri Akademik Araştırmalar Dergisi, 2(5), 11-21.

Gall, M. D., Borg, W. R., \& Gall, J. P. (1996). Educational Research: An İntroduction. Longman Publishing.

Gültekin, Y., \& Bulut, Y. (2016). Bitcoin ekonomisi: Bitcoin eko-sisteminden doğan yeni sektörler ve analizi. Adnan Menderes Üniversitesi Sosyal Bilimler Enstitüsü Dergisi, 3(3), 82-92.

Kostakis, V., \& Giotitsas, C. (2014). The (A) political economy of Bitcoin. Triplec: Communication, Capitalism \& Critique. Open Access Journal For A Global Sustainable Information Society, 12(2), 431-440.

Köroğlu, S. A. (2015). Literatür taramasi üzerine notlar ve bir tarama tekniği. GIBD Dergi, (01), 61-69.

Karaağaç, G. A., \&Amp; Altınırmak, S. (2018). En yüksek piyasa değerine sahip on kripto paranın birbirleriyle etkileşimi. Muhasebe ve Finansman Dergisi, (79), 123-138.

Moore, W., \& Stephen, J. (2016). Should Cryptocurrencies be included in the portfolio of international reserves held By Central Banks?. Cogent Economics \& Finance, 4(1), 1147119.

Safran, B. (2021). Kripto para ve finansal piyasalar. İktisat Alanında Seçilmiş Konular-2, 117.

Turan, Z. (2018). Kripto paralar, Bitcoin, blockchain, petro gold, dijital para ve kullanım alanları. Ömer Halisdemir Üniversitesi İktisadi Ve İdari Bilimler Fakültesi Dergisi, 11(3), 1-5.

Yumuşaker, M. C. (2019). Kripto para ve tipleri, Bitcoin olgusu ve muhasebesi. Opus Uluslararası Toplum Araştırmaları Dergisi, 12, $1007-1029$.

Yavuz, G. Ü. L. (2020). Kripto paralar ve portföy çeşitlendirmesi. Dumlupınar Üniversitesi Sosyal Bilimler Dergisi, (65), $125-141$. 